\title{
Distribution of the Colonoscopic Adenoma Detection Rate According to Age: Is Recommending Colonoscopy Screening for Koreans Over the Age of 50 Safe?
}

\author{
Taeseok Bae, Yunhyung Ha, Changkyun Kim, Jihyun Lee, Kwangil Ha, Sanghyun Shin, Youngcheol Lee, \\ Yoonsik Kang \\ Department of Surgery, Joy-Full Hospital, Seoul, Korea
}

Purpose: This study was conducted to determine the distributions of the polyp detection rate (PDR) and the adenoma detection rate (ADR) according to age by analyzing the polypectomy results.

Methods: A total of 10,098 patients who underwent a colonoscopy in 2013 were included in this study. Chi-square and logistic regression statistical analyses were performed using SPSS ver. 19.

Results: The mean age of the patients was 52.7 years old (median, $54 \pm 12.52$ years; range, 14 to 92 years). A total of 6,459 adenomatous polyps (61.7\%) from a total of 10,462 polyps were eliminated. The PDR was 50.9\% $(5,136 / 10,098)$, and the. ADR was $35.4 \%(3,579 / 10,098)$. The male-to-female ratio was $51.3 \%: 48.7 \%$, with a male-to-female ADR ratio of $42.8 \%$ : $27.7 \%(\mathrm{P}<0.001)$. In the age distribution, the values of the ADR were $0 \%$ for patients in their 10 's, $6.3 \%$ for those in their 20 's, $14.0 \%$ for those in their 30 's, $28.7 \%$ for those in their 40 's, $38.4 \%$ for those in their 50 's, $46.2 \%$ for those in their 60 's, $55.8 \%$ for those in their 70 's, $56.1 \%$ for those in their 80 's, and $33.3 \%$ for those in their 90 's. In males, the values of the ADR were $0 \%, 9.1 \%, 17.1 \%, 37.8 \%, 48.2 \%, 53.6 \%, 61.7 \%, 59.1 \%$, and $33.3 \%$ for the same age distribution, and a steep increase was found between patients in their 30's and patients in their 40's. Significant $(P<0.001)$ factors influencing the ADR included sex, previous colonoscopy experience, polypectomy method, and age of more than 40 years.

Conclusion: In considering the adenoma carcinoma sequence, $28.7 \%$ of people, especially $37.8 \%$ of males in their 40 's showed adenomatous polyps. Whether an earlier first-time colonoscopy will have better results in preventing colorectal cancer should be investigated and discussed.

Keywords: Adenoma; Age distribution; Colonic polyps; Colonoscopy

\section{INTRODUCTION}

A national polyp study (NPS) in United States revealed that a colonoscopic polypectomy reduced the mortality of colorectal

Received: December 12, 2014 - Accepted: January 24, 2015

Correspondence to: Taeseok Bae, M.D.

Department of Surgery, Joy-Full Hospital, 122 Dogok-ro, Gangnam-gu, Seoul 139-839, Korea

Tel: +82-2-570-1208, Fax: +82-2-570-1233

E-mail: fender73@hanmail.net

This abstract was reported at International colorectal research summit 2014

(c) 2015 The Korean Society of Coloproctology

This is an open-access article distributed under the terms of the Creative Commons Attribution NonCommercial License (http://creativecommons.org/licenses/by-nc/3.0) which permits unrestricted noncommercial use, distribution, and reproduction in any medium, provided the original work is properly cited. cancer (CRC) as well as the incidence of CRC $[1,2]$. Colonoscopy has become the mainstream of cancer screening from the viewpoint of diagnostic and therapeutic availability. A total of 536,399 CRC cases were found in the national CRC screening program in Korea in 2005 by using fecal occult blood tests, double contrast barium enemas, and colonoscopy. In 2012, a total of 2,165,445 CRC cases were found due to the major social concern about well-being and the relatively easier access to medical services. From 1999 to 2011, the incidence of CRC continuously increased in both male and female Koreans [3].

Now, several indications seem to suggest that the results of colonoscopy, including the cecal intubation rate, withdrawal time, adenoma detection rate (ADR), polyp-missing rate, and interval cancer, need to be evaluated in order to improve the efficacy of colonoscopy [4]. Considering the adenoma carcinoma sequence, 
removing as many polyps as possible in order to prevent CRC may seem reasonable. However, despite past efforts, CRC is the second most common cancer in males and the fourth most common cancer in females. CRC is the second most common cancer in 15- to 60-year-old males according to an age-specific incidence report in Korea [5]. Frequent observations for CRC patients younger than 50 years are likely to hamper the recommended colonoscopy screening for patients older than 50 years and go against current official guidelines. Therefore, the purpose of this study was to determine whether the analysis of the ADR and the polyp detection rate (PDR) according to age would reveal features that would support improved guidelines for the use of screening colonoscopy for the effective prevention of CRC in Korea.

\section{METHODS}

\section{Patients}

A total of 10,088 of 10,238 cases enrolled in a screening program between January 2013 and December 2013 were selected for this study. A total of 150 cases were excluded for diagnostic purposes due to significant signs (weight loss, gastrointestinal bleeding, and chronic diarrhea), therapeutic colonoscopies for control of complications (e.g., bleeding and microperforation), repeated polypectomy for too many polyps, and short-term follow-up for confirming uncertain resection margins. Although 10 teenagers were not included in any other screening programs, colonoscopy was performed for anal bleeding due to hemorrhoids or anal fissures and irritable bowel syndromes. They were included in this study for the analyses of the age distributions. No patients who participated in the study had a personal history of inflammatory bowel disease or CRC. Each patient's age, sex, history of polyps, presence of polyps, method of polypectomy, and pathologic reports were reviewed retrospectively.

\section{Colonoscopy}

A total of 13 doctors with experience in more than 500 cases of polypectomies were involved in the colonoscopies. All examinations were conducted with the Elvis Lucera CV 260 colonoscope system (Olympus, Tokyo, Japan). Patients were instructed to take Picolight or Colyte 6 hours before the colonoscopy for bowel cleansing. All detected polyps were removed using snare, punch biopsy instruments or endoscopic submucosal dissection (ESD). The size of the polyp was estimated by using the size of openpunch forceps. Most sessile polyps less than $5 \mathrm{~mm}$ were removed with open forceps. Some subpedunculated or sessile polyps, even if they were less than $5 \mathrm{~mm}$, were removed with a snare when complete resection was possible. Although most patients with polyps agreed to have polyps removed if detected during inspections, a polypectomy could not be performed for 6 patients (a total of 13 polyps). Five of those six patients refused due to financial difficulties, and one had a medical problem associated with Warfarin medication.

\section{Statistical analysis}

The PDR was defined as the proportion of patients for whom colonoscopy was conducted and at least one polyp was identified. The ADR was defined as the proportion of patients in whom an adenoma was detected. The ADR and the PDR were calculated and were analyzed according to age, sex, pathology type, previous history of colonoscopy, and history of personal or familial polypectomy by using the Pearson chi-square test. For the multivariate analysis, a logistic regression test with the above factors was used. Statistical analyses were performed with IBM SPSS Statistics ver. 19.0 (IBM Co., Armonk, NY, USA), and a P-value of less than 0.05 was considered statistically significant.

\section{RESULTS}

\section{Patients' characteristics}

Of 10,462 polyps found in colonoscopy, 10,098 patients were involved in this study. The mean age of the patients was 52.7 years (range, 14-92 years; median, $54 \pm 12.5$ years), including 5,179 males (51.3\%) and 4,919 females (48.7\%). According to age, 10 patients $(0.1 \%)$ were in their teens, $302(3.0 \%)$ were in their 20 's, $1,310(13.0 \%)$ were in their 30 's, $2,185(21.6 \%)$ were in their 40 's, $3,111(30.8 \%)$ were in their 50's, $2,270(22.5 \%)$ were in their 60's, $825(8.2 \%)$ were in their 70 's, $82(0.8 \%)$ were in their 80 's, and 3 $(0.03 \%)$ were in their 90 's. Among them, 5,504 patients had experienced a previous colonoscopy (54.5\%), including 2,725 patients in whom polyps had been detected at the previous colonoscopy. The most frequently used method was a snare polypectomy (7,213, 68.8\%), including endoscopic mucosal dissection (EMR). A cold open-forceps polypectomy $(3,055,29.2 \%)$ was the second most common method. An ESD was performed in 194 cases of the total 10,475 polyps (1.9\%) (Table 1 ).

\section{Pathology}

The total 10,462 polyps, excluding 13 polyps that had not been removed, included 6,459 adenomatous polyps (61.7\%) and 3,996 nonadenomatous polyps (38.2\%). Most adenomatous polyps were tubular adenomas $(5,978,57.1 \%)$. An adenocarcinoma was found in 75 cases $(0.7 \%)$. Of the nonadenomatous polyps, hyperplastic polyps $(3,996,86.3 \%)$ accounted for almost all nonadenomatous polyps. Other types included inflammatory polyps with or without lymphoid hyperplasia, carcinoid tumors, lipomas, etc. (Table 1).

\section{ADR and PDR with age distribution}

In this study, the PDR was $50.9 \%(5,136 / 10,098)$, and the ADR was $35.4 \%(3,579 / 10,098)$. Regarding the PDR/ADR ratio, males (59.8\%/42.8\%), experienced doctors (53.0\%/37.0\%), and patients with a personal history of a polypectomy $(59.2 \% / 41.7 \%)$ were associated with the detection of more polyps, and this result had statistical significance $(\mathrm{P}<0.001)$. Regarding a family history of polyps or CRC, cases without a family history showed more pol- 


\section{Coloproctology

yps than patients with a family history of polyps or CRC with 1st relatives or 2 nd relatives. Patients who had experienced a previous colonoscopy tended to have more polyps, and this result was statistically significant $(P=0.017)$. However, for the ADR, no statistically significant differences existed between the index colonoscopy group and the surveillance colonoscopy group.

When all patients were classified into PDR or ADR groups, ages of 30 years, 40 years, and 50 years had statistically significant distributions $(\mathrm{P}<0.001)$. The most dramatic contrast was seen at age 30 . In every group, the ADR difference between younger age and older age was more than $10 \%$ (Table 2). Both the PDR and the

Table 1. Characteristics of patients

\begin{tabular}{|c|c|}
\hline Characteristic & Value \\
\hline \multicolumn{2}{|l|}{ Age (yr) } \\
\hline Mean \pm SD (range) & $52.7 \pm 12.5(14-92)$ \\
\hline \multicolumn{2}{|l|}{ Gender } \\
\hline Male & $5,179(51.3)$ \\
\hline Female & $4,919(48.7)$ \\
\hline \multicolumn{2}{|l|}{ History } \\
\hline Previous colonoscopy (+) & $5,504(54.5)$ \\
\hline Previous polypectomy (+) & $2,725(27.0)$ \\
\hline \multicolumn{2}{|l|}{ Family history of polyps or colorectal cancer } \\
\hline 1st Relatives & $1,119(11.1)$ \\
\hline 2nd Relatives & $90(0.9)$ \\
\hline Polyps & 10,475 \\
\hline Snare & $7,213(68.8)$ \\
\hline Punch & $3,055(29.2)$ \\
\hline ESD & $194(1.9)$ \\
\hline No polypectomy & $13(0.1)$ \\
\hline Histology & 10,462 \\
\hline Adenomatous polyp & $6,459(61.7)$ \\
\hline Adenocarcinoma & $75(0.7)$ \\
\hline Tubular adenoma & $5,978(57.1)$ \\
\hline Tubulovillous adenoma & $323(3.1)$ \\
\hline Serrated adenoma & $83(0.8)$ \\
\hline Nonadenomatous polyp & 3,996 (38.2) \\
\hline Hyperplastic polyp & $3,450(33.0)$ \\
\hline Inflammatory polyp & $484(4.6)$ \\
\hline Carcinoid tumor & $23(0.2)$ \\
\hline Submucosal lipoma & $16(0.2)$ \\
\hline Leiomyoma & $11(0.1)$ \\
\hline $\begin{array}{l}\text { Juvenile polyp/xanthoma/lymphangietasia/ } \\
\text { malignant lymphoma }\end{array}$ & $5 / 3 / 3 / 1(0.1)$ \\
\hline
\end{tabular}

Values are presented as number (\%) unless otherwise indicated. $\mathrm{SD}$, standard deviation.
ADR were increasingly correlated with age. The PDR/ADR ratios were $20 \% / 0 \%$ for patients in their teens, $16.9 \% / 6.3 \%$ for patients in their 20 's, $33 \% / 14.0 \%$ for patients in their 30 's, $43.5 \% / 28.7 \%$ for patients in their 40 's, $54.3 \% / 38.4 \%$ for patients in their 50 's, $61.2 \% / 46.2 \%$ for patients in their 60 's, $68.7 \% / 55.8 \%$ for patients in their 70's, $65.9 \% / 56.1 \%$ for patients in their 80 's, and 33.3\%/33.3\% for patients in their 90's $(\mathrm{P}<0.001)$ (Figs. 1, 2). When all age distributions were subdivided by gender, men in their 40's showed an $\mathrm{ADR}$ of $37.8 \%$, which was 2.16 folds more than that of women in their 40's. The steepest ascent in ADR was discovered between the ages of 30's and 40's (Fig. 2).

\section{ADR and PDR by histology type and distribution}

The incidence of adenomatous polyps increased according to age regardless of type. As for CRC, adenocarcinomas were found in patients in their teens and 20's. From patients in their 30's, the incidence constantly increased to patients in their 70's, but was lower for patients in their 80's and 90's. The incidence of CRC was not different between patients in their 40's and 50's ( $0.5 \%$ vs.

Table 2. PDR and ADR variations associated with the characteristics of the patients

\begin{tabular}{|c|c|c|c|c|}
\hline Variable & PDR (\%) & P-value & ADR $(\%)$ & P-value \\
\hline Overall & 50.9 & & 35.4 & \\
\hline Gender & & $<0.001$ & & $<0.001$ \\
\hline Male & 59.8 & & 42.8 & \\
\hline Female & 41.5 & & 27.7 & \\
\hline Doctors & & $<0.001$ & & $<0.001$ \\
\hline$\geq 5,000$ & 53.0 & & 37.0 & \\
\hline$<5,000$ & 46.1 & & 32.0 & \\
\hline Family history & & 0.007 & & 0.002 \\
\hline None & 51.1 & & 35.7 & \\
\hline $1 s t$ & 50.6 & & 34.6 & \\
\hline 2nd & 34.4 & & 17.8 & \\
\hline Previous colonoscopy & & 0.017 & & 0.358 \\
\hline No & 49.6 & & 35.0 & \\
\hline Yes & 51.9 & & 35.8 & \\
\hline Personal polyp history & & $<0.001$ & & $<0.001$ \\
\hline No & 47.8 & & 33.1 & \\
\hline Yes & 59.2 & & 41.7 & \\
\hline ESD:Snare:Punch & & & $89.4: 76.5: 45.9$ & $<0.001$ \\
\hline \multicolumn{5}{|l|}{ Age (yr) } \\
\hline$\geq 30:<30$ & $51.9: 17.0$ & $<0.001$ & $36.4: 6.1$ & $<0.001$ \\
\hline$\geq 40:<40$ & $54.9: 29.9$ & $<0.001$ & $39.8: 12.5$ & $<0.001$ \\
\hline$\geq 50:<50$ & $58.8: 37.7$ & $<0.001$ & $43.7: 21.8$ & $<0.001$ \\
\hline
\end{tabular}

PDR, polyp detection rate; $A D R$, adenoma detection rate; ESD, endoscopic submucosal dissection. 
$0.4 \%)$. As for tubular adenomas, adenomas were most commonly found in patients in their 70's (53.7\%). Relatively earlier detection in patients in their 20's was observed. In nonadenomatous polyps, the increasing tendencies of hyperplastic polyps and inflam-

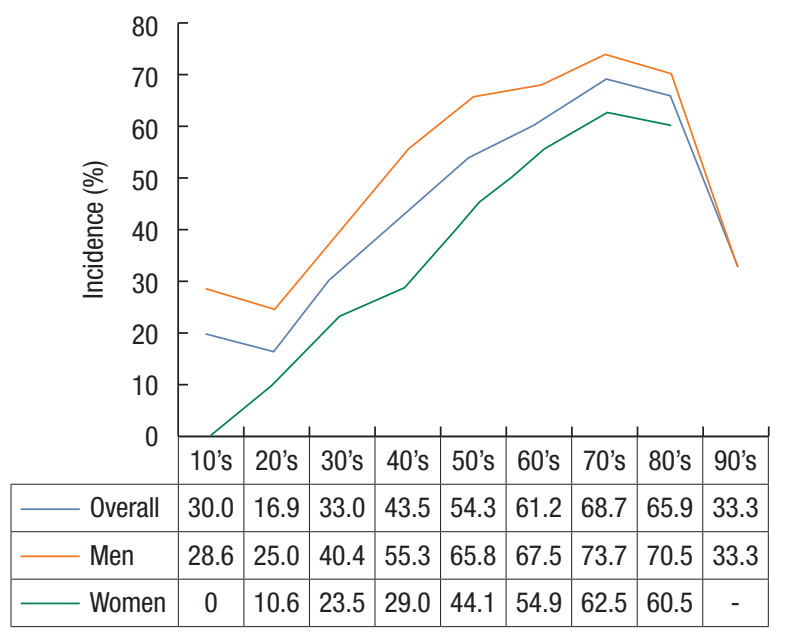

Fig. 1. Polyp detection rate by age distribution and gender $(\mathrm{P}=0.000)$.

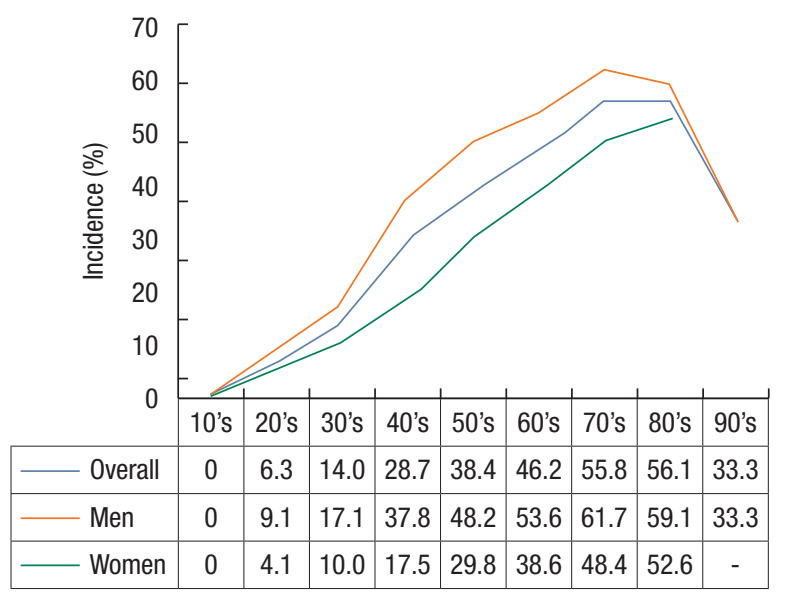

Fig. 2. Adenoma detection rate by age distribution and gender $(\mathrm{P}=$ 0.000). matory polyps were similar to those of adenomatous polyps. Carcinoid tumors occurred sporadically without relation to age (Table 3).

\section{ADR variations associated with patients' characteristics (multivariate analysis)}

Sex, history of personal colonoscopic exposure, method of polypectomy, age in the 40's, and age in the 50's were related to the incidence of adenomatous polyps $(\mathrm{P}<0.001$; odds ratio $[\mathrm{OR}]: 0.712$, $0.683,0.661,2.800$, and $1.643 ; 95 \%$ confidence interval [CI]: $0.627-0.810,0.581-0.797,0.01-0.726,2.206-3.553$, and $1.401-$ 1.928). Both classifications at age in the 40's and the 50's were statistically significant. However, the OR was higher for ages in the 40 's than for ages in the 50's (95\% CI, 2.800 vs. 1.643). Familial history of CRC or polyps, personal history of a polypectomy, and age in the 30's were not correlated with the occurrence of an adenoma $(\mathrm{P}=0.83)$ (Table 4$)$.

\section{DISCUSSION}

The results of this study may reflect the incidence of colorectal polyps in the general population of Korea. According to this

Table 4. Adenoma detection rate multivariate analysis by using the logistic regression test

\begin{tabular}{lrl}
\hline Variable & P-value & \multicolumn{1}{c}{ OR (95\% Cl) } \\
\hline Gender & $<0.001$ & $0.712(0.627-0.810)$ \\
Family history of polyps & 0.830 & $1.020(0.855-1.216)$ \\
Personal history of colonoscopy & $<0.001$ & $0.681(0.81-0.797)$ \\
Personal history of polypectomy & 0.683 & $1.035(0.878-1.219)$ \\
Polypectomy methods & $<0.001$ & $0.661(0.601-0.726)$ \\
Age (yr) & & \\
$\geq 30$ & 0.493 & $1.235(0.675-2.259)$ \\
$\geq 40$ & $<0.001$ & $2.800(2.206-3.553)$ \\
$\geq 50$ & $<0.001$ & $1.643(1.401-1.928)$ \\
Doctor's experience $\geq 5,000$ cases & 0.375 & $1.064(0.928-1.221)$ \\
\hline
\end{tabular}

$\mathrm{OR}$, odds ratio; $\mathrm{Cl}$, confidence interval.

Table 3. Polyp detection rate, adenoma detection rate, and age distribution by histology type

\begin{tabular}{lccccccccccc}
\hline Histology & $\begin{array}{c}\text { Teens } \\
(\mathrm{n}=10)\end{array}$ & $\begin{array}{c}\text { 20's } \\
(\mathrm{n}=302)\end{array}$ & $\begin{array}{c}30 \text { 's } \\
(\mathrm{n}=1,310)\end{array}$ & $\begin{array}{c}40 \text { 's } \\
(\mathrm{n}=2,185)\end{array}$ & $\begin{array}{c}50 \text { 's } \\
(\mathrm{n}=3,111)\end{array}$ & $\begin{array}{c}60 \text { 's } \\
(\mathrm{n}=2,270)\end{array}$ & $\begin{array}{c}70 \text { 's } \\
(\mathrm{n}=825)\end{array}$ & $\begin{array}{c}\text { 80's } \\
(\mathrm{n}=82)\end{array}$ & $\begin{array}{c}\text { 90's } \\
(\mathrm{n}=3)\end{array}$ & $\begin{array}{c}\text { Total } \\
\text { P-value }\end{array}$ \\
\hline Adenocarcinoma & 0 & 0 & 0.2 & 0.5 & 0.4 & 1.2 & 1.7 & 9.8 & 0 & 0.7 & $<0.001$ \\
Tubular adenoma & 0 & 4.6 & 12.2 & 26.5 & 37.0 & 44.0 & 53.7 & 50.0 & 33.3 & 33.6 & $<0.001$ \\
Tubulovillous adenoma & 0 & 0 & 0.6 & 1.6 & 2.4 & 1.9 & 2.3 & 2.4 & 0 & 1.8 & 0.002 \\
Serrated adenoma & 0 & 0.7 & 0.5 & 0.5 & 0.5 & 1.1 & 1.2 & 3.7 & 0 & 0.7 & 0.009 \\
Hyperplastic polyp & 20.0 & 8.9 & 19.1 & 21.6 & 26.6 & 28.1 & 30.5 & 24.4 & 0 & 24.6 & $<0.001$ \\
Inflammatory polyp & 10.0 & 3.0 & 2.9 & 2.7 & 3.1 & 4.7 & 4.4 & 4.9 & 0 & 3.5 & 0.009 \\
Carcinoid tumor & 0 & 1.0 & 0.5 & 0.3 & 0.1 & 0.1 & 0.2 & 0 & 0 & 0.2 & 0.068 \\
\hline
\end{tabular}


study, a Korean colonoscopist may expect that over $50 \%$ of the patients enrolled in a screening program will possibly have polyps. More than one-third of the patients might have adenomas. The incidence of adenomatous polyps in this study showed a somewhat similar or increasing tendency compared to those in previous reports on colonoscopy screening in average-risk Koreans [6-8]. Choe et al. [6] reported the incidence of adenomatous polyps to be $21.6 \%$ in 2007 . Park et al. [7] reported an incidence of $33.2 \%$ in 2009 based on a prospective multicenter survey. Kim et al. [8] reported a $26.7 \%$ incidence in a community-based secondary hospital. In general in the United States, the threshold value for the $\mathrm{ADR}$ is recommended to be $25 \%$ in men and $15 \%$ in women [9]. The increasing prevalence of CRC in Korea, in spite of the increasing number of polypectomies recently, raises concerns about the guidelines for CRC screening.

In our study, the incidence of adenomatous polyps in the general population enrolled in screening programs was influenced by age. The incidence of adenomatous polyps was significantly different in patients below the age of 40 and above the age of 50 . Age is one of the most important factors affecting the incidence of adenomatous polyps. Several reports have confirmed that the overall incidence of colorectal adenomas increases linearly with age [7, 8]. In this study, the ADR of men was about 1.5 folds higher than that of women. In Western countries, as well as in Korea, the incidence of adenomatous polyps has been reported to be about 1.31.5 fold higher in men than in women $[5,7]$. Especially for men between $40-49$ years, adenomatous polyps are suspected to be nearly $40 \%$ of all polyps. Thus, the first time for colonoscopy screening should be differentiated by gender. The exact reason for this remains unexplained. However, these epidemiologic findings may be important for launching a strategy for the screening program in which men and the elderly are considered preferentially as suitable candidates for colonoscopy screening.

In this study, the incidences of adenomatous polyps and CRC in patients in their 40 's were $28.7 \%$ and $0.5 \%$, respectively. In the current guidelines, the screening for CRC among Koreans at average risk is recommended to begin at the age of 50 [10]. This recommendation was established due to a dramatic increase in the incidence of CRC after the age of 50. According to the 2008 statistics of the Korea Central Cancer Registry, the incidence rates of CRC by age group were 28.8 per 100,000 for patients in their 40 's, 82.5 per 100,000 for patients in their 50's, 174.5 per 100,000 for patients in their 60 's, and 245.7 per 100,000 for patients in their 70's [10]. In a multicenter prospective study in Korea [7], the incidence of adenomatous polyps was reported to be $28.1 \%$ for patients in their 40 's, which was similar to our results. Considering that, in this study, no differences in the incidences of CRC existed between patients in their 40's and patients in their 50's and that the independent factor influencing the $\mathrm{ADR}$ was an age indicator of patients in their age 40's in this study $(\mathrm{P}<0.001 ; \mathrm{OR}, 2.800$; 95\% CI, 2.206-3.553), the increasing prevalence of CRC in Korea might be correlated with earlier occurrence and progression of adenomatous polyps. However, the results of this study could not be used to determine whether a 10-year earlier colonoscopy screening would reduce the incidence of CRC more effectively. In this study, some selection bias might have existed because colonoscopy screening was conducted in a large metropolitan center without involving rural areas. Therefore, a nationwide prospective study representing the general population of Korea should be started to evaluate the cost-effectiveness of a 10-year earlier colonoscopy screening for the reduction of CRC.

The methods of polypectomy in this study included a snare polypectomy, a cold-forceps polypectomy, an EMR, and ESD. The selection of the method was based on the size and the shape of the polyp. Any polyp of more than $6 \mathrm{~mm}$ in size was not removed by using a cold-forceps polypectomy. However, some polyps of less than $5 \mathrm{~mm}$ could be removed by using a snare polypectomy due to their subpedunculated shapes. Our results revealed the ADR was affected by the polypectomy method. Therefore, this could mean that the larger the polyps were, the more prevalent were the neoplastic changes that had occurred. The size of the polyp is an important factor that influences the progression of an adenoma $[11,12]$. An adenoma at $1 \mathrm{~cm}$ or more in diameter with highgrade dysplasia of a villous or tubulovillous type is defined as an advanced adenoma. The overall miss rate for adenomatous polyps ranged from $15 \%$ to $24 \%$. For an advanced adenoma with a diameter of more than $1 \mathrm{~cm}$, the miss rate was reported to be $6 \%$ to $11 \%[13,14]$. Kaminski et al. [15] reported that the risk of interval cancer was significantly higher in patients who underwent colonoscopies performed by endoscopists whose ADRs were less than $20 \%$, compared with the results of endoscopists whose ADRs were more than $20 \%$. Therefore, the meticulous inspection of adenomatous polyps might be important factor in screening availability.

The incidence of CRC is rapidly rising. In 2011, newly registered CRC patients were 17,157 men and 10,955 women, and the overall number of CRC patients in Korea was 154,816 [5]. Especially in men, the incidence of CRC nearly doubled from 1999 to 2011 $[3,5]$. Although the increased rate of participation in the national cancer screening program is likely to be partly responsible for the increased incidence rates of CRC, the rapid Westernization of lifestyle and dietary habits has also contributed to the increased incidence of CRC [10]. However, the ambiguous expatiation is not enough to explain the entire phenomenon. In this study, risk factors that could influence the prevalence of CRC, including alcohol consumption, smoking, and unhealthy eating habits, were not evaluated. The identification of such causal relationships should yield a complete strategy for cancer prevention.

In conclusion, age and sex were independent factors in adenoma detection. The groups older than 40 years showed a significant difference from groups younger than 40 years. So, meticulous inspection for mucosal changes regardless of their young age, may be required to reduce the life-threatening risks from adenomatous polyps to CRC. Thus, whether the current guidelines are suitable 
for the present trend of CRC in Korea needs to be debated and discussed, and such interactions may lead to a need for the current guidelines to be reinforced.

\section{CONFLICTS OF INTEREST}

No potential conflict of interest relevant to this article was reported.

\section{REFERENCES}

1. Winawer SJ, Zauber AG, Ho MN, O'Brien MJ, Gottlieb LS, Sternberg SS, et al. Prevention of colorectal cancer by colonoscopic polypectomy. The National Polyp Study Workgroup. N Engl J Med 1993;329:1977-81.

2. Zauber AG, Winawer SJ, O’Brien MJ, Lansdorp-Vogelaar I, van Ballegooijen M, Hankey BF, et al. Colonoscopic polypectomy and long-term prevention of colorectal-cancer deaths. N Engl J Med 2012;366:687-96.

3. Ministry of Health \& Welfare, National Cancer Center. Cancer facts \& figure 2014 in the Republic of Korea. Goyang: National Cancer Center; 2014.

4. Moon CM. Quality indicators of colonoscopy: old and news. Korean Soc Gastrointest Endosc 2013;49:134-6.

5. Jung KW, Won YJ, Kong HJ, Oh CM, Lee DH, Lee JS. Cancer statistics in Korea: incidence, mortality, survival, and prevalence in 2011. Cancer Res Treat 2014;46:109-23.

6. Choe JW, Chang HS, Yang SK, Myung SJ, Byeon JS, Lee D, et al. Screening colonoscopy in asymptomatic average-risk Koreans: analysis in relation to age and sex. J Gastroenterol Hepatol 2007; 22:1003-8.
7. Park HW, Byeon JS, Yang SK, Kim HS, Kim WH, Kim TI, et al. Colorectal neoplasm in asymptomatic average-risk Koreans: The KASID Prospective Multicenter Colonoscopy Survey. Gut Liver 2009;3:35-40.

8. Kim JK, Choi YS, Suh JP, Lee IT, Youk EG, Lee DS. Results of screening colonoscopy in asymptomatic average-risk Koreans at a community-based secondary hospital. Korean J Gastrointest Endosc 2010;41:266-72.

9. Imperiale TF, Wagner DR, Lin CY, Larkin GN, Rogge JD, Ransohoff DF. Results of screening colonoscopy among persons 40 to 49 years of age. N Engl J Med 2002;346:1781-5.

10. Lee BI, Hong SP, Kim SE, Kim SH, Kim HS, Hong SN, et al. Korean guidelines for colorectal cancer screening and polyp detection. Clin Endosc 2012;45:25-43.

11. Winawer SJ, Zauber AG, Fletcher RH, Stillman JS, O'Brien MJ, Levin B, et al. Guidelines for colonoscopy surveillance after polypectomy: a consensus update by the US Multi-Society Task Force on Colorectal Cancer and the American Cancer Society. Gastroenterology 2006;130:1872-85.

12. Yang DH, Hong SN, Kim YH, Hong SP, Shin SJ, Kim SE, et al. Korean guidelines for postpolypectomy colonoscopy surveillance. Clin Endosc 2012;45:44-61.

13. Rex DK, Cutler CS, Lemmel GT, Rahmani EY, Clark DW, Helper DJ, et al. Colonoscopic miss rates of adenomas determined by back-to-back colonoscopies. Gastroenterology 1997;112:24-8.

14. Ahn SB, Han DS, Bae JH, Byun TJ, Kim JP, Eun CS. The miss rate for colorectal adenoma determined by quality-adjusted, back-toback colonoscopies. Gut Liver 2012;6:64-70.

15. Kaminski MF, Regula J, Kraszewska E, Polkowski M, Wojciechowska U, Didkowska J, et al. Quality indicators for colonoscopy and the risk of interval cancer. N Engl J Med 2010;362:1795-803. 